Research Article

\title{
Experimental Study on the Shear Performance of Steel-Truss-Reinforced Concrete Beam-Column Joints
}

\author{
Dafu Cao $(D$, Jiaqi Liu $(D)$, Wenjie Ge $(D$, and Rui Qian \\ College of Civil Science and Engineering, Yangzhou University, Yangzhou, China \\ Correspondence should be addressed to Wenjie Ge; gewj@yzu.edu.cn
}

Received 28 January 2021; Accepted 30 April 2021; Published 15 May 2021

Academic Editor: Luís C. Neves

Copyright (c) 2021 Dafu Cao et al. This is an open access article distributed under the Creative Commons Attribution License, which permits unrestricted use, distribution, and reproduction in any medium, provided the original work is properly cited.

In order to study the influence of the axial compression ratio and steel ratio on the shear-carrying capacity of steel-truss-reinforced beam-column joints, five shear failure interior joint specimens were designed. The effect of different coaxial pressure ratios $(0.1$, 0.2 , and 0.3 ) and steel contents on the strain, ultimate bearing capacity, seismic performance, and failure pattern of cross-inclined ventral and chord bars in the joint core area was investigated. The experimental results show that the load-displacement hysteretic curves of all test specimens exhibit a bond-slip phenomenon. With the increase of the axial compression ratio, the ultimate bearing capacity of the joint core increases by $3.4 \%$ and $5.9 \%$, respectively. While the ductility decreases by $10.3 \%$ and $13.1 \%$, and the energy consumption capacity decreases by $3.2 \%$ and $5.8 \%$, respectively. The shear capacity and ductility of the member with cross diagonal ventral steel angle in the joint core are increased by $12.9 \%$ and $13.4 \%$, respectively. The shear capacity and ductility of the joint can be significantly improved by increasing the amount of steel in the core area. The expression of shear capacity suitable for this type of joint is obtained by fitting analysis, which can be used as a reference for engineering design.

\section{Introduction}

The steel-reinforced concrete (SRC) composite structure is a new type of structure based on steel and concrete structures, which can combine the advantages of both $[1,2]$. Compared to ordinary reinforced concrete, the strength of components can be increased by a factor of $1.5-2.0$, stiffness is improved, and section size is reduced, thus increasing the usable area of the building and making the spatial arrangement of the building more flexible [3]. As an important part of the connecting beam-column, under the vertical load and seismic action, its stress is more complex. The frame joint mainly bears the axial force, shear force, and bending moment transmitted by the beam and column. The joint is subjected to multiple stresses of compression, bending, and shearing [4]. If the joint is not equipped with enough stirrups and its resistance to shear deformation is weak, the core area of the joint undergoes shear failure under the action of principal tensile stress. Many scholars have conducted significant experimental research on SRC joints. Kanno $[5,6]$ conducted low-cyclic load tests on multiple SRC beam- reinforced concrete column frame joints and found that the axial compression ratio of concrete strength core area size affects the hysteretic performance of joints. Ryoichi [7] analyzed the hysteretic properties of steel beam-reinforced concrete column joints and described the design and mechanical properties of the combined beam-column joints used for seismic design. Chou [8] found that, to avoid shear failure in the core zone, the shear strength can be enhanced by the use of the core zone compensation steel plate. Kadarningsih [9] found that the shear strength of the joints can be improved by using section steel as the frame to replace the transverse longitudinal bars. Mirghaderi [10] suggested a new moment connection between steel beams and a reinforced concrete column (RCS) and described the force transfer mechanisms and design procedure. Chen [11] studied the shear capacity of the middle joints, but the proposed model did not consider the influence of axial pressure on the shear mechanism of the steel web; hence, it did not apply to the calculation of the shear capacity of the joints under high axial pressure. Tang [12] conducted experimental research on four SRC beam-column frame 
composite joints and compared them with ordinary reinforced concrete joints. It was found that SRC joints exhibit better shear bearing capacity and seismic performance. Ketiyot [13] found that cast-in-place joints exhibit good ductility and energy dissipation capacity, but for the precast components, the crack at the lap joint is the main failure mode and the seismic performance is weaker than that for the cast-in-place joints.

In the full-web-type SRC column frame joints, the beam steel bones should be disconnected on both sides of the column steel bones, and the joints should be connected via welding and other forms. Thus, based on the SRC structure, a steel-truss-reinforced concrete (STRC) structure is proposed in this research by using a steel truss as the major reinforcement for a conventional concrete structure. The beam skeleton in the open-web SRC frame joint adopted in this study can directly pass through the inside of the chord angle of the column [14]. Previously, the behavior and strength of SRC beam-column joints with single-sided and two-sided force inputs have been studied [15], wherein the applicability of the strength superposition method to joint shear strength was assessed. Zen [16] and Chen [17] tested the influence of axial compression ratio, angle steel size, and steel content on the seismic performance of STRC joints. Experimental results demonstrate that the ductility and energy dissipation capacity of this structure are better than those of reinforced concrete joints. Regarding failure modes, core shear failure occurs in all the joints in the test. Deng [18] fabricated eight groups of STRC beam-column joints and explored the influence of the angle steel size and axial compression ratio on the seismic performance. The test results showed that increasing the axial compression ratio was beneficial to the bearing capacity but unfavorable to hysteretic performance.

In conclusion, STRC structures can reflect good seismic performance. However, there are few studies on the bearing capacity and seismic performance of interior joints, especially their shear-carrying capacity. Therefore, this paper focuses on these and the specific methodology is as follows: First, low-cycle reversed loading tests are conducted on five STRC beam-column joints. Second, the influence of axial compression ratio and steel ratio on the ductility and seismic performance of the open-web SRC structure joints were studied through the hysteretic curve and skeleton curve obtained from the tests. This study presents significant experimental results to elucidate the unknown behavior of STRC frame joints.

\section{Materials and Methods}

2.1. Specimen Design. In this study, all specimen designs and test procedures followed the criteria specified in the Chinese concrete design codes (GB 50010-2010 (SAC, 2010)) and specification of testing methods for the testing of earthquake-resistant buildings (JGJ101 96 (SAC, 1996)) and concrete structures (GB50152 92 (SAC, 1992)). The variables of the specimens are the axial pressure ratio and the amount of steel in the core area. All five joints are designed to scale; the scale ratio is $1: 2$. The specimen numbers are J-1-J-5. Among J-1-J-3, the configurations of the chord and ventral bar are the same, whereas the axial pressure ratio is different. The central position of the J-4 member is not equipped with a cross diagonal ventral steel angle, whereas the central position of the J-5 member is equipped with an L $40 \times 4$ steel angle. The concrete details of the specimens are presented in Table 1. The design of the joint specimen is shown in Figure 1.

\subsection{Measuring Point Arrangement and Loading Criteria.} In the process of component loading, the actuator of the electrohydraulic servo system automatically records the load-displacement curve of the column end. Strain readings of chord bars and diagonal bar angles are collected by strain gauges at each measuring point. The specific arrangement of measuring points is shown in Figure 2. Cracks are drawn on the whitewashed concrete surface with a black mark. As shown in Figure 3, shear deformation in the core area is recorded by two LVTDs arranged at a $45^{\circ}$ angle in the node core area [19].

The $50 \mathrm{~T}$ hydraulic servo system actuator was used for cyclic loading, and the node loading position was at the end of the columns. The specific loading device is shown in Figure 4, and the test site diagram is shown in Figure 5

Traditional loading methods include force-controlled loading and displacement-controlled loading. Force-controlled loading is generally used for specimens with high stiffness and displacement-controlled loading is used for members with strong displacement sensitivity. Later, combined with their respective characteristics, the forcedisplacement mixed control method emerged [20]. The loading system adopted in this test is the force-displacement mixed control loading system specified in the specification of testing methods for the testing of earthquake-resistant buildings (JGJ101 96 (SAC, 1996)). The specific loading criteria are shown in Figure 6 . The loading process is divided into two stages. Before the yield of the specimen, the forcecontrolled loading is used, and the displacement-controlled loading is used after the specimen yield. The displacement corresponding to the yield load is taken for each loading step. Each level of load is repeated once before yielding and three times after yielding.

2.3. Material Properties. The grade of concrete used for the specimens is C30; the concrete mix proportion is presented in Table 2. According to the Chinese Standard Test Methods for the mechanical properties of ordinary concrete (GB/T50081-2002), the strengths of three sets of standard cube test blocks cast under the same curing conditions were measured before the component test; the results are presented in Table 3. The angle steel and steel plate used in the beam and column framework are Q235. The mechanical properties of angle steel and steel connectors were tested according to the Chinese methods of tensile testing for metallic materials at room temperature (GB/T 228-2010); the results are presented in Table 4. 
TABLE 1: Component design parameters.

\begin{tabular}{|c|c|c|c|c|c|c|c|c|}
\hline \multirow{2}{*}{$\begin{array}{l}\text { Specimen } \\
\text { number }\end{array}$} & \multicolumn{2}{|c|}{ Column } & \multicolumn{2}{|c|}{ Beam } & \multicolumn{2}{|c|}{ Web member } & \multirow{2}{*}{$\begin{array}{c}\text { Axial } \\
\text { compression } \\
\text { ratio }\end{array}$} & \multirow{2}{*}{$\begin{array}{c}\text { Cross diagonal } \\
\text { ventral steel angle }\end{array}$} \\
\hline & $\begin{array}{l}\mathrm{B} \times \mathrm{H} \\
(\mathrm{mm})\end{array}$ & $\begin{array}{l}\text { Chord } \\
\text { member }\end{array}$ & $\begin{array}{l}\mathrm{B} \times \mathrm{H} \\
(\mathrm{mm})\end{array}$ & $\begin{array}{l}\text { Chord } \\
\text { member }\end{array}$ & $\begin{array}{c}\text { Vertical web } \\
\text { member }\end{array}$ & $\begin{array}{c}\text { Diagonal web } \\
\text { member }\end{array}$ & & \\
\hline$J-1$ & $350 \times 350$ & $\mathrm{~L} 70 \times 8$ & $220 \times 350$ & $\mathrm{~L} 63 \times 8$ & $\mathrm{~L} 40 \times 4$ & $\mathrm{~L} 20 \times 3$ & 0.1 & $\mathrm{~L} 20 \times 3$ \\
\hline $\mathrm{J}-2$ & $350 \times 350$ & $\mathrm{~L} 70 \times 8$ & $220 \times 350$ & $\mathrm{~L} 63 \times 8$ & $\mathrm{~L} 40 \times 4$ & $\mathrm{~L} 20 \times 3$ & 0.2 & $\mathrm{~L} 20 \times 3$ \\
\hline$J-3$ & $350 \times 350$ & $\mathrm{~L} 70 \times 8$ & $220 \times 350$ & $\mathrm{~L} 63 \times 8$ & $\mathrm{~L} 40 \times 4$ & $\mathrm{~L} 20 \times 3$ & 0.3 & $\mathrm{~L} 20 \times 3$ \\
\hline$J-4$ & $350 \times 350$ & $\mathrm{~L} 70 \times 8$ & $220 \times 350$ & $\mathrm{~L} 63 \times 8$ & $\mathrm{~L} 40 \times 4$ & $\mathrm{~L} 20 \times 3$ & 0.2 & -- \\
\hline$J-5$ & $350 \times 350$ & $\mathrm{~L} 70 \times 8$ & $220 \times 350$ & L63 × 8 & $\mathrm{~L} 40 \times 4$ & $\mathrm{~L} 20 \times 3$ & 0.2 & $\mathrm{~L} 40 \times 4$ \\
\hline
\end{tabular}

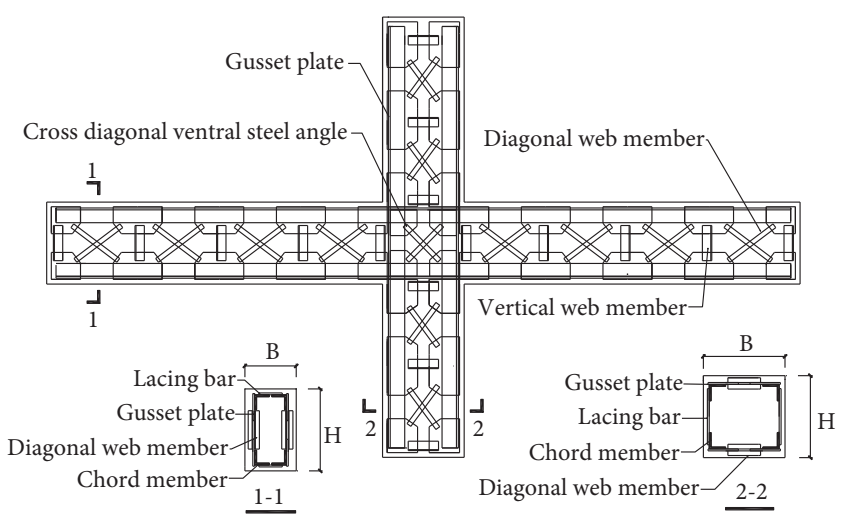

(a)

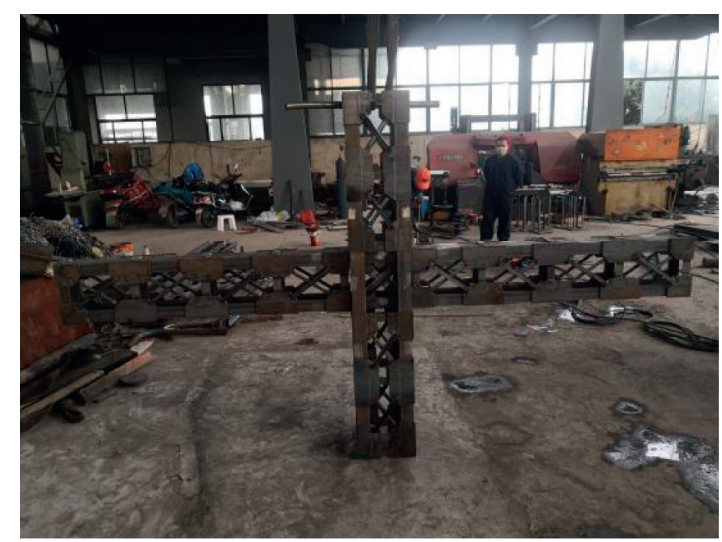

(b)

FIGURE 1: Design of joint specimen: (a) reinforcement style and (b) photograph of reinforcement skeleton before casting.

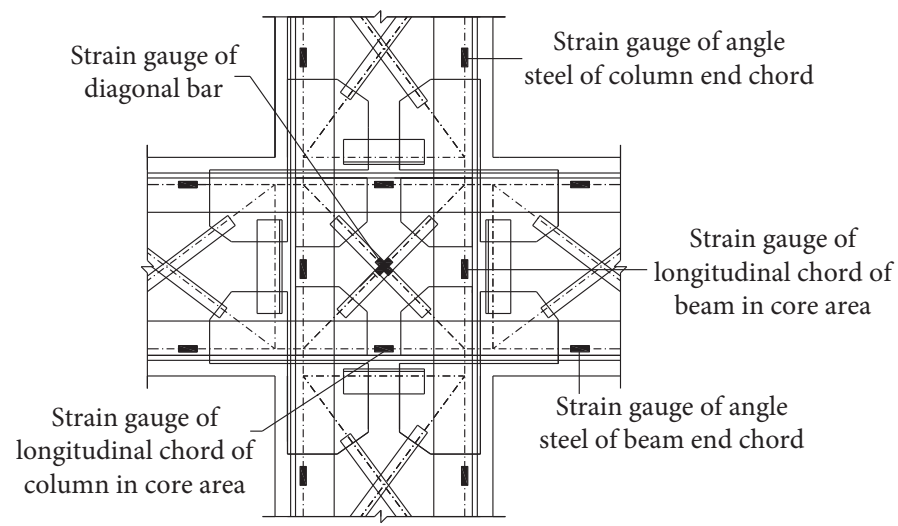

Strain gauge

FIgURE 2: Arrangement of strain measuring points.

\subsection{Experimental Observations}

2.4.1. Loading Process and Phenomena. Component J-1 was selected to describe the failure process of the joint. First, an axial force of $175 \mathrm{kN}$ was applied to the top of the column. A reciprocating cyclic load was then applied in the horizontal direction of the column end. The outward direction of the actuator's head is positive (marked as “+”). When the load was increased to $+36 \mathrm{kN}, 2$ vertical fine cracks appeared at the bottom of the left beam. When the load increased to
$-36 \mathrm{kN}, 2$ fine cracks appeared at the bottom of the right beam, which is symmetric with the cracks appearing at the bottom of the left beam. Simultaneously, the subtle left beam cracks closed. When the load increased to $+84 \mathrm{kN}$, all cracks in the reverse loading closed and the cracks at the bottom of the left beam extended slightly on the original basis. When the load increased to $+105 \mathrm{kN}$ (at this point displacement is $15 \mathrm{~mm}$, marked as $1 \Delta$ ), a new fine crack appeared at the bottom of the left beam. The original crack extended further. The longest crack length was approximately $12 \mathrm{~mm}$. The first 


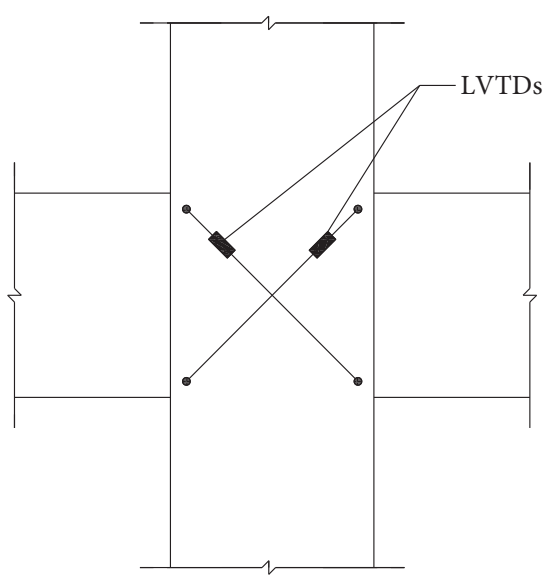

Figure 3: LVTD layout.

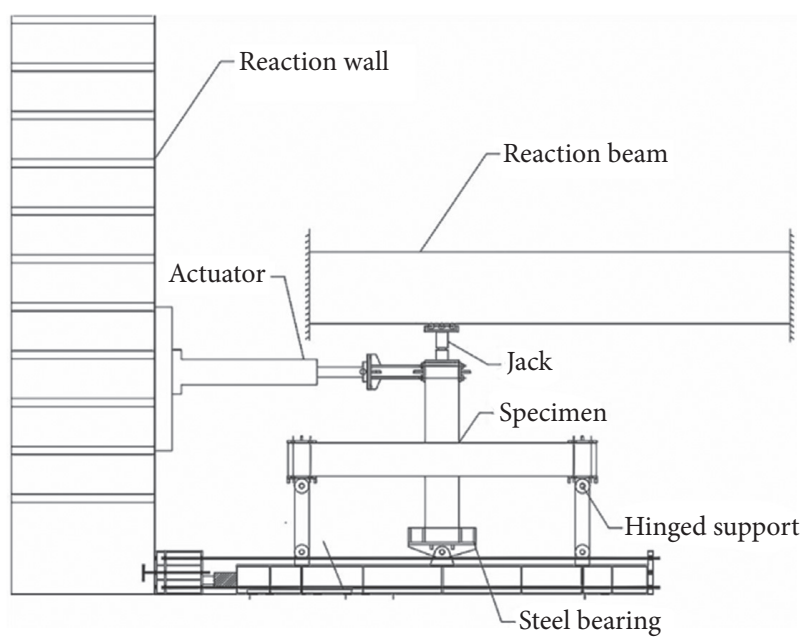

FIgURE 4: Loading device.

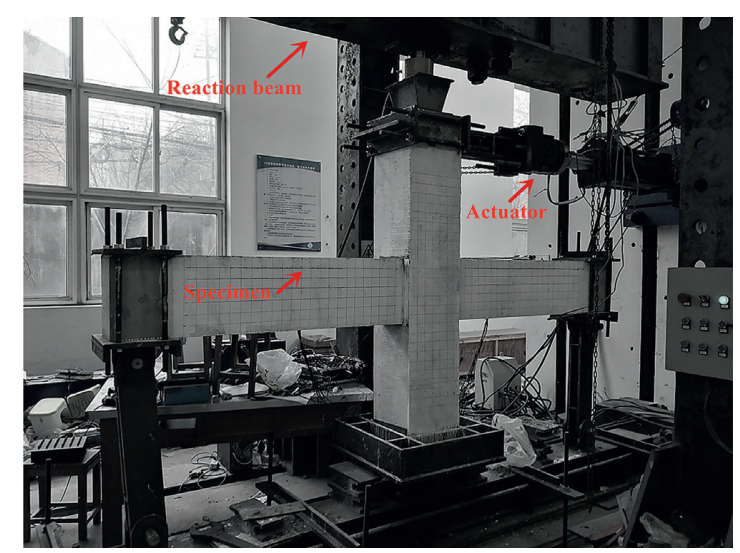

Figure 5: Test on-site.

upper crack appeared on the upper part of the right beam, $14 \mathrm{~mm}$ from the column edge. A first diagonal crack appeared in the core area, with a length of approximately $95 \mathrm{~mm}$. When the displacement increased to $-1 \Delta$, the first crack appeared in the upper part of the left beam. The cracks

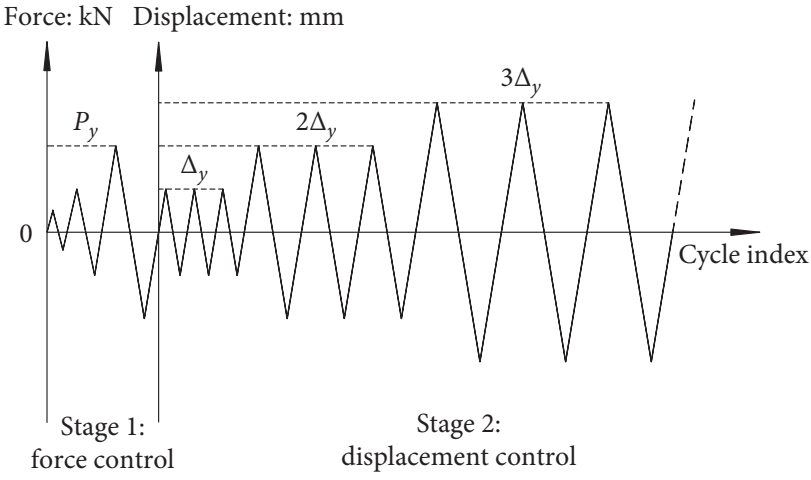

Figure 6: Loading system.

in the original position of the right beam were slightly developed, and a thin crack appeared along the opposite of the diagonal direction in the core area, with a length of $105 \mathrm{~mm}$. The original diagonal crack closed. When the displacement increased to $+2 \Delta$, the cracks at the bottom of the left beam and the top of the right beam extended by approximately $5 \mathrm{~mm}$. The original diagonal crack in the core area extended rapidly, and several new short cracks appeared parallel to this diagonal crack. When the displacement increased to $-2 \Delta$, many thin cracks appeared along the opposite of the diagonal direction in the core area. The original diagonal cracks continued to expand to both sides. When the displacement increased to $+3 \Delta$, the crack at the beam end no longer extended, and almost no new crack appeared in the core area. The original diagonal crack continued to develop toward the column end, with a maximum width of $1.73 \mathrm{~mm}$. When the displacement increased to $-3 \Delta$, no new cracks appeared in the core area, whereas the original cracks continued to develop with a maximum width of $1.73 \mathrm{~mm}$. When the displacement increased to $+4 \Delta$, the crack width in the core zone increased, a small amount of concrete was crushed, the longest oblique crack extended to approximately $10 \mathrm{~mm}$ outside the beam-column interface, and the widest crack was $2.95 \mathrm{~mm}$. When the displacement increased to $-4 \Delta$, the concrete was locally crushed diagonally in the core area, with a maximum crack width of $3.88 \mathrm{~mm}$. When the displacement increased to $\pm 5 \Delta$, the concrete in the core area was crushed and spalled in a large area. When the displacement increased to $+6 \Delta$, the concrete in the core area drums outwards and the bearing capacity of members significantly decreased (the bearing capacity drops below $85 \%$ of the ultimate bearing capacity), the test member eventually breaks, and the test ends. The feature points of load values during the whole procedure are presented in Table 5.

2.4.2. Crack Distribution and Failure Pattern. The crack distribution and failure modes of all STRC beam-column joints are shown in Figure 7.

\section{Results}

3.1. Hysteresis Behavior. A hysteresis curve can reflect the bearing capacity, stiffness, ductility, and seismic energy 
TABle 2: Concrete mix.

\begin{tabular}{lccccc}
\hline Design strength & Water: $\mathrm{kg} / \mathrm{m}^{3}$ & Cement: $\mathrm{kg} / \mathrm{m}^{3}$ & Sand: $\mathrm{kg} / \mathrm{m}^{3}$ & Stone: $\mathrm{kg} / \mathrm{m}^{3}$ & Coal ash: $\mathrm{kg} / \mathrm{m}^{3}$ \\
\hline C30 & 225 & 300 & 75 & 711 & 1089 \\
\hline
\end{tabular}

TABle 3: Mechanical properties of concrete.

\begin{tabular}{lcccc}
\hline $\begin{array}{l}\text { Specimen } \\
\text { number }\end{array}$ & $\begin{array}{c}\text { Cube compressive strength: } \\
\mathrm{MPa}\end{array}$ & $\begin{array}{c}\text { Axial compressive strength: } \\
\mathrm{MPa}\end{array}$ & $\begin{array}{c}\text { Axial tension strength: } \\
\mathrm{MPa}\end{array}$ & $\begin{array}{c}\text { Elasticity modulus: } \\
\mathrm{MPa}\end{array}$ \\
\hline H1 & 33.5 & 25.46 & 2.73 & $3.09 \times 104$ \\
H2 & 33.7 & 25.61 & 2.73 & $3.10 \times 104$ \\
H3 & 35.4 & 26.90 & 2.81 & $3.14 \times 104$ \\
Average & 34.2 & 25.99 & 2.76 & $3.11 \times 104$ \\
\hline
\end{tabular}

TABle 4: Mechanical properties of steel.

\begin{tabular}{lccc}
\hline Steel type & Yield strength: $\mathrm{MPa}$ & Ultimate strength: MPa & Elasticity modulus: MPa \\
\hline L70 $\times 8$ & 280.2 & 481.3 & $2.0 \times 10^{5}$ \\
L63 $\times 8$ & 280.6 & 491.2 & $2.0 \times 10^{5}$ \\
L40 $\times 4$ & 273.3 & 465.9 & $2.0 \times 10^{5}$ \\
L20 $\times 3$ & 279.6 & 427.6 & $2.0 \times 10^{5}$ \\
8 mm steel plate & 269.4 & 448.4 & $2.0 \times 10^{5}$ \\
\hline
\end{tabular}

TABLE 5: Feature points of test results.

\begin{tabular}{lccccc}
\hline Specimen number & Loading direction & Yield load: $\mathrm{kN}$ & Yield displacement: $\mathrm{mm}$ & Ultimate load: $\mathrm{kN}$ & Failure displacement: $\mathrm{mm}$ \\
\hline \multirow{2}{*}{$\mathrm{J}-1$} & Positive & 176.85 & 32.29 & 203.15 & 89.28 \\
& Negative & -179.92 & -33.20 & -204.58 & -95.59 \\
\hline \multirow{2}{*}{$\mathrm{J}-2$} & Positive & 181.67 & 31.60 & 210.87 & 79.85 \\
& Negative & -182.93 & -33.37 & -208.32 & -84.58 \\
\hline \multirow{2}{*}{$\mathrm{J}-3$} & Positive & 185.42 & 33.57 & 215.04 & 83.52 \\
& Negative & -187.79 & -35.81 & -219.89 & -86.13 \\
\hline \multirow{2}{*}{$\mathrm{J}-4$} & Positive & 174.29 & 30.56 & 201.15 & 75.82 \\
& Negative & -172.04 & -30.92 & -197.85 & -75.28 \\
\hline \multirow{2}{*}{$\mathrm{J}-5$} & Positive & 205.71 & 33.40 & 227.36 & -12.14 \\
& Negative & -204.58 & -36.49 & -228.06 & -102.87 \\
\hline
\end{tabular}

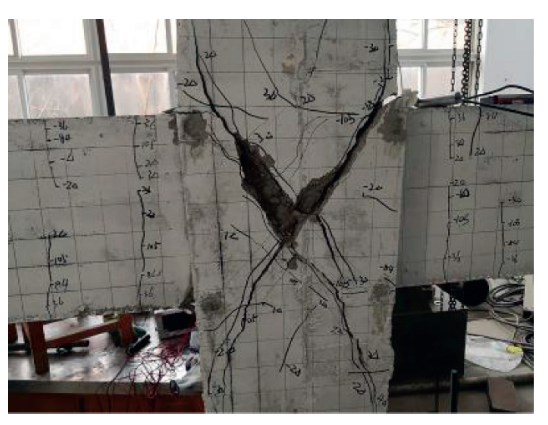

(a)

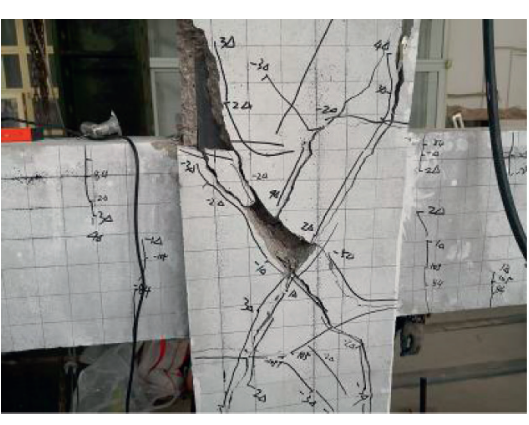

(b)

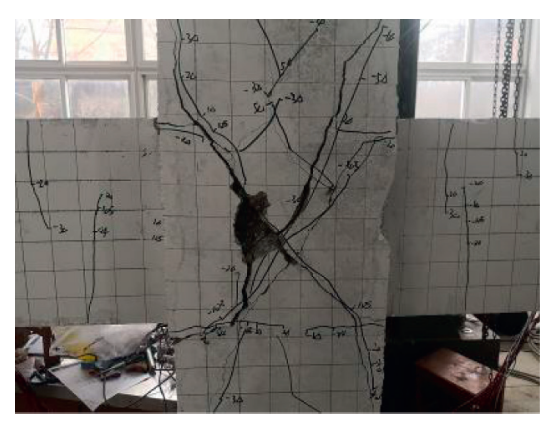

(c)

Figure 7: Continued. 


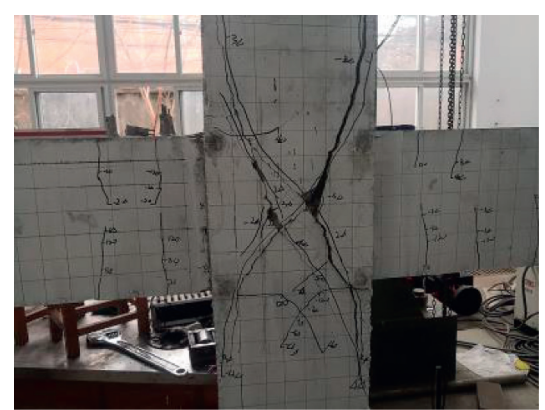

(d)

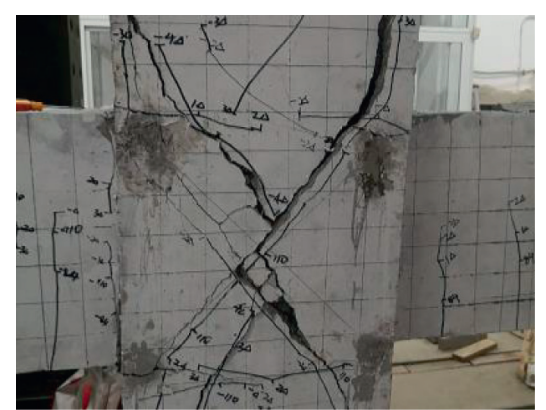

(e)

FIGURE 7: Crack distribution of components. (a) J-1, (b) J-2, (c) J-3, (d) J-4, and (e) J-5.

dissipation of the joint. Moreover, it is also an important basis for seismic performance assessment. This work presents the load displacement for the evaluation of energy dissipation behaviors of the joint specimens. The load-displacement hysteresis loops are presented in Figure 8.

As shown in Figure 8, when the component is in the elastic stage of loading, the hysteresis curve in the loading and unloading processes changes along the original trajectory (approximately), the area of the hysteresis curve is very small, and there is almost no residual deformation. With a further increase in displacement, cracks appeared successively in the beam end and core area. The hysteresis curve area gradually increased, energy dissipation capacity of the joint gradually increased, slope of the curve gradually slowed, and stiffness further decreased. After the specimens reached the peak load, the pinching phenomenon occurred between the steel truss and concrete and the shape exhibited by the hysteresis curve is large at both ends and thin in the middle. From the hysteresis curve obtained in this test, it can be seen that the hysteresis curves of the five specimens are all inversely S-shaped, with an obvious pinching phenomenon. This is caused by the smooth surface of the angle steel and the large contact area with concrete. And the ability for energy absorption is reduced due to the pinching effect [21]. However, compared with reinforced concrete joints, the hysteresis curve obtained in this study takes on a fuller shape and its seismic performance is better than that of ordinary reinforced concrete.

3.2. Skeleton Curves. Load-displacement skeleton curves are produced by connecting the peak values of every loading step. The skeleton curve can directly reflect the stress change process of the structure. After simple treatment, the peak yield and failure loads of the structure can be obtained. The curve can also intuitively reflect the strength, ductility, and other characteristics of the specimen structure. To study and compare various parameters, several skeleton curves with the same design parameters were combined for comparative analysis, as shown in Figure 9. The analysis first reveals that an increase in axial compression ratio is beneficial for increasing the shear capacity of the specimen while the specimens with a small axial compression ratio exhibited a gentle curve decline and strong deformation capacity. For example, J-1, J-2, and J-3 are designed with the same shaped steel ratio but their axial compression ratios are $0.1,0.2$, and 0.3, respectively, as shown in Figure 9(a). The peak load of $\mathrm{J}-3(215 \mathrm{kN})$ increased in comparison with that of J-2 $(210 \mathrm{kN})$. At the same time, the peak load of J-2 $(210 \mathrm{kN})$ increased in comparison with that of J-1 $(203 \mathrm{kN})$. However, as the deformation increases from 45 to $60 \mathrm{~mm}$, the bearing capacity of J-3 deteriorates rapidly (from 215 to $201 \mathrm{kN}$ ) in comparison to that of J-1 (from 203 to $198 \mathrm{kN}$ ). The second finding is that the ultimate bearing capacity of specimens with cross diagonal bars in the core area is larger than that of specimens with small steel ratios, ultimate displacement of the specimens with a shaped steel ratio is relatively large, and decline of the skeleton curve is relatively slow. For example, $\mathrm{J}-2, \mathrm{~J}-4$, and $\mathrm{J}-5$ are designed with the same axial compression ratio but their cross diagonal ventral steel angles are L $20 \times 3,0$, and L $40 \times 4$, respectively (see Table 1 ). It can be seen from Figure $9(\mathrm{~b})$ that the peak load of J-5 $(227 \mathrm{kN})$ is increased in comparison with that of J-2 $(210 \mathrm{kN})$. Simultaneously, the peak load of $\mathrm{J}-2(210 \mathrm{kN})$ is increased in comparison with that of $\mathrm{J}-4(201 \mathrm{kN})$. The ultimate displacement of J-5 is $98 \mathrm{~mm}$, which is larger than the ultimate displacement of J-4 $(80 \mathrm{~mm})$. Third, the failure process of the STRC beam-column joints underwent three stages-elastic, yield, and failure-and the skeleton curves of the five specimens in the elastic stage coexist.

3.3. Ductility Coefficient. The displacement ductility coefficient is often used to quantify the ductility performance of frame structures, which is defined as the relevant ultimate displacement divided by the yielding displacement, expressed as

$$
\mu=\frac{\Delta_{u}}{\Delta_{v}}
$$

where $\Delta_{u}$ is the ultimate displacement at the column end (in this study, the ultimate displacement corresponding to a structural bearing capacity falling to $85 \%$ of the peak load) and $\Delta_{y}$ is the yielding displacement at the column end. In addition, considering that the structure skeleton curve has no obvious turning point, the yield displacement $\Delta_{y}$ cannot be directly determined. In this study, the common equivalent energy method was adopted [22]. The specific procedure is shown in Figure 10. It can be seen that, by drawing 


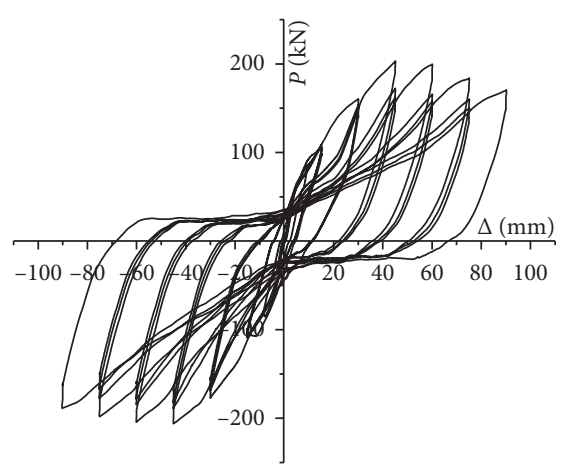

(a)

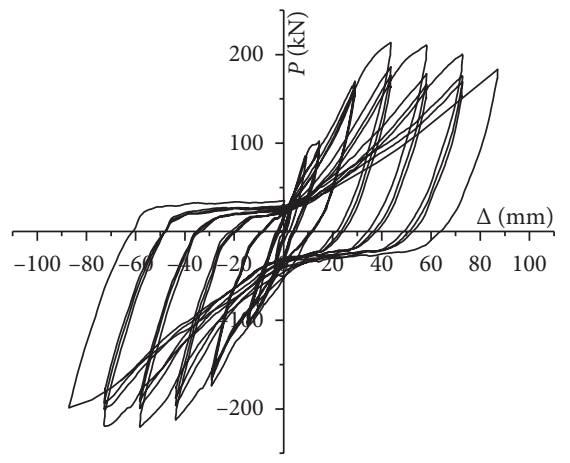

(c)

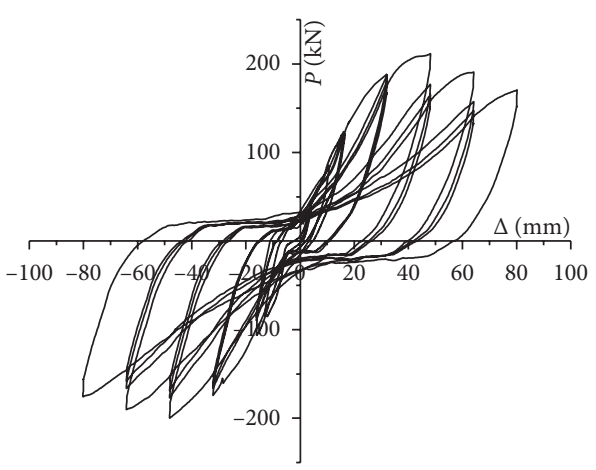

(b)

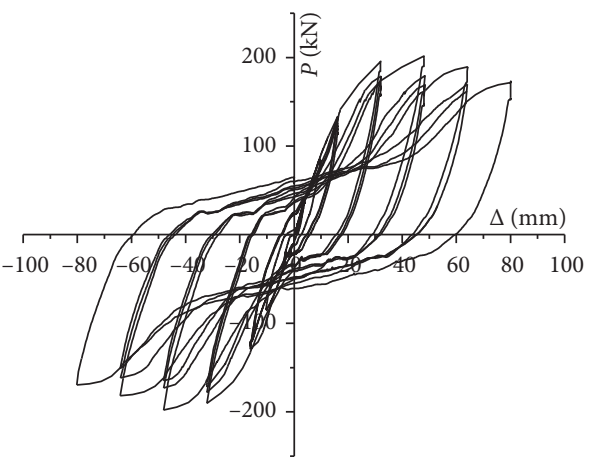

(d)

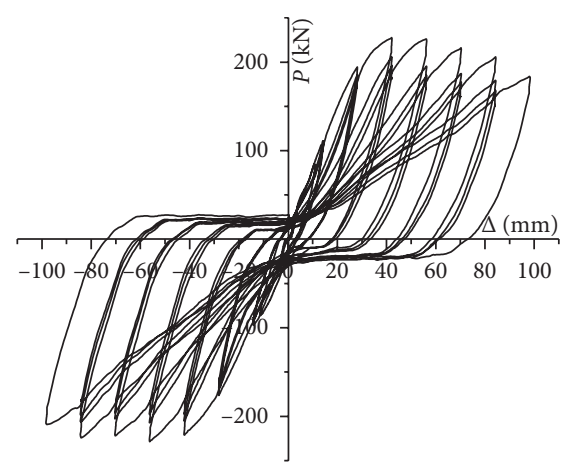

(e)

Figure 8: Load-displacement hysteretic curve. (a) J-1, (b) J-2, (c) J-3, (d) J-4, and (e) J-5.

two straight lines that produce two equal areas, $\mathrm{A}$ and $\mathrm{B}$, the yielding point $\mathrm{E}$ can be determined as the intersection point of the load-displacement curve and a vertical line starting from the top corner [23]. The yield strength is evaluated at point E, which is the coordinate value $P_{y}$ along the $P$-axis. The displacement ductility coefficients of all specimens were calculated and are presented in Table 6. It can be seen from Table 6 that, with an increase in the axial compression ratio, the ductility coefficient of the STRC beam-column joints decreases and the deformation ability reduces, whereas intersecting diagonal bars in the core area can improve the ductility of the specimens. For example, the ductility coefficients of the J-1, J-2, and J-3 components are 2.82, 2.53, and 2.45 , respectively, showing a decreasing trend. The ductility coefficients of the J-4, J-2, and J-5 components are 2.46, 2.53, and 2.79 , respectively, showing an increasing trend.
3.4. Equivalent Viscous-Damping Coefficient. The energy dissipation is an indication of the specimen capacity to be stressed until failure and defines the energy that could be dissipated before the loss of system stability [24]. Under the action of seismic loads, a stronger energy dissipation capacity of the frame nodes results in greater generated damping and more absorbed energy, which can effectively avoid damage to the nodes and reduce damage to the house. The area enclosed in the hysteresis loop can be adopted to evaluate the energy absorption capacity. To quantitatively demonstrate the energy dissipation efficiency, the area of each hysteresis loop during the loading steps can be calculated. Then, an equivalent viscous-damping coefficient was suggested to consider energy dissipation [25]. The calculation diagram is shown in Figure 11 and the equivalent viscous-damping coefficient can be calculated as follows: 


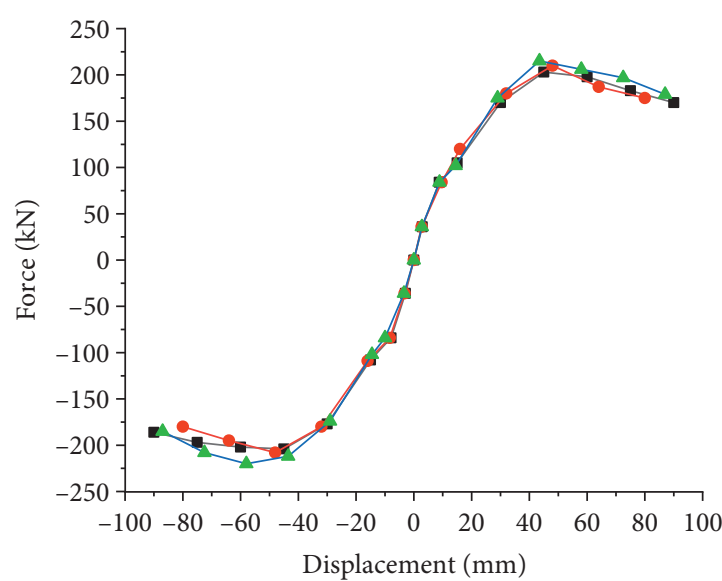

- $\mathrm{J}-1$

- J-2

$\rightarrow \mathrm{J}-3$

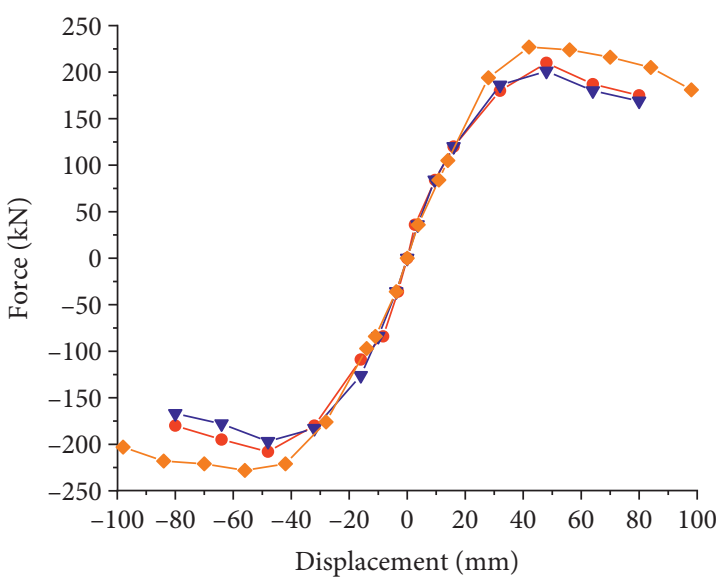

$\rightarrow-\mathrm{J}-2$

$-\nabla-\mathrm{J}-4$

$\rightarrow-\mathrm{J}-5$

(a)

(b)

FIGURE 9: (a) Skeleton curve comparison (different coaxial compression ratio); (b) (different amount of steel).

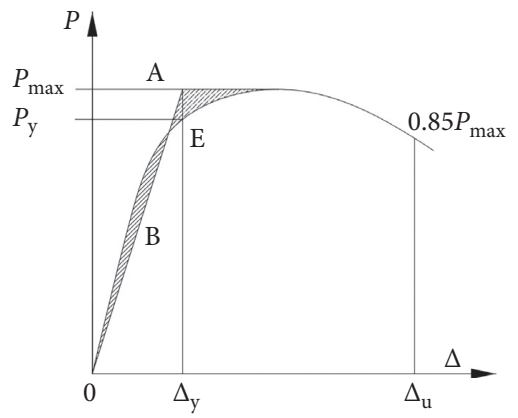

FIgURE 10: Determination of yielding strength.

TABle 6: Displacement ductility coefficient.

\begin{tabular}{|c|c|c|c|c|c|}
\hline $\begin{array}{l}\text { Specimen } \\
\text { number }\end{array}$ & $\begin{array}{l}\text { Loading } \\
\text { direction }\end{array}$ & Yield displacement $\left(\Delta_{y}\right): \mathrm{mm}$ & $\begin{array}{l}\text { Ultimate displacement }\left(\Delta_{u}\right) \text { : } \\
\mathrm{mm}\end{array}$ & $\begin{array}{l}\text { Ductility coefficient } \\
(\mu)\end{array}$ & Average \\
\hline $\mathrm{J}-1$ & $\begin{array}{l}\text { Positive } \\
\text { Negative }\end{array}$ & $\begin{array}{c}32.29 \\
-33.20\end{array}$ & $\begin{array}{c}89.28 \\
-95.59\end{array}$ & $\begin{array}{l}2.76 \\
2.88\end{array}$ & 2.82 \\
\hline $\mathrm{J}-2$ & $\begin{array}{l}\text { Positive } \\
\text { Negative }\end{array}$ & $\begin{array}{c}31.60 \\
-33.37 \\
\end{array}$ & $\begin{array}{c}79.85 \\
-84.58 \\
\end{array}$ & $\begin{array}{l}2.53 \\
2.53 \\
\end{array}$ & 2.53 \\
\hline $\mathrm{J}-3$ & $\begin{array}{l}\text { Positive } \\
\text { Negative }\end{array}$ & $\begin{array}{c}33.57 \\
-35.81\end{array}$ & $\begin{array}{c}83.52 \\
-86.13\end{array}$ & $\begin{array}{l}2.49 \\
2.41\end{array}$ & 2.45 \\
\hline$J-4$ & $\begin{array}{l}\text { Positive } \\
\text { Negative }\end{array}$ & $\begin{array}{c}30.56 \\
-30.92 \\
\end{array}$ & $\begin{array}{c}75.82 \\
-75.28 \\
\end{array}$ & $\begin{array}{l}2.48 \\
2.43\end{array}$ & 2.46 \\
\hline$J-5$ & $\begin{array}{l}\text { Positive } \\
\text { Negative }\end{array}$ & $\begin{array}{c}33.40 \\
-36.49\end{array}$ & $\begin{array}{c}92.14 \\
-102.87\end{array}$ & $\begin{array}{l}2.76 \\
2.82\end{array}$ & 2.79 \\
\hline
\end{tabular}

$$
h_{e}=\frac{S_{\mathrm{ABCD}}}{2 \pi \cdot\left(S_{\mathrm{BOE}+\mathrm{DOF}}\right)},
$$

where $S_{\mathrm{ABCD}}$ is the shaded area enclosed by a hysteretic loop and $S_{\mathrm{BOE}+\mathrm{DOF}}$ is the sum of the areas of the triangles corresponding to the upper and lower vertices of a hysteretic ring. Table 7 presents the equivalent viscous-damping coefficient of the first positive cycle for the five specimen joints under different loading regimes.

It can be seen from Table 7 and Figure 12 that the energy dissipation capacity of all specimen joints increases with the increase in displacement. At the same time, the axial pressure ratio and intersecting diagonal bars in the core area affect the energy absorption capacity. For example, the 


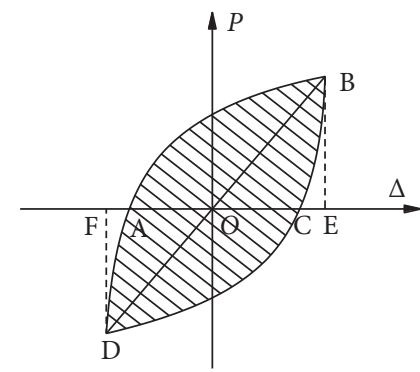

Figure 11: Energy dissipation capacity calculation diagram.

TABLE 7: Equivalent viscous-damping coefficient.

\begin{tabular}{lccccccc}
\hline Specimen number & $1 \Delta$ & $2 \Delta$ & $3 \Delta$ & $4 \Delta$ & $5 \Delta$ & $6 \Delta$ \\
\hline J-1 & 0.139 & 0.145 & 0.153 & 0.155 & 0.161 & 0.177 & - \\
J-2 & 0.116 & 0.123 & 0.142 & 0.150 & 0.164 & - \\
J-3 & 0.121 & 0.124 & 0.131 & 0.146 & 0.148 & 0.170 \\
J-4 & 0.121 & 0.143 & 0.170 & 0.180 & 0.205 & - \\
J-5 & 0.092 & 0.100 & 0.113 & 0.119 & 0.131 & 0.142 & 0.161 \\
\hline
\end{tabular}

quivalent viscous-damping coefficient

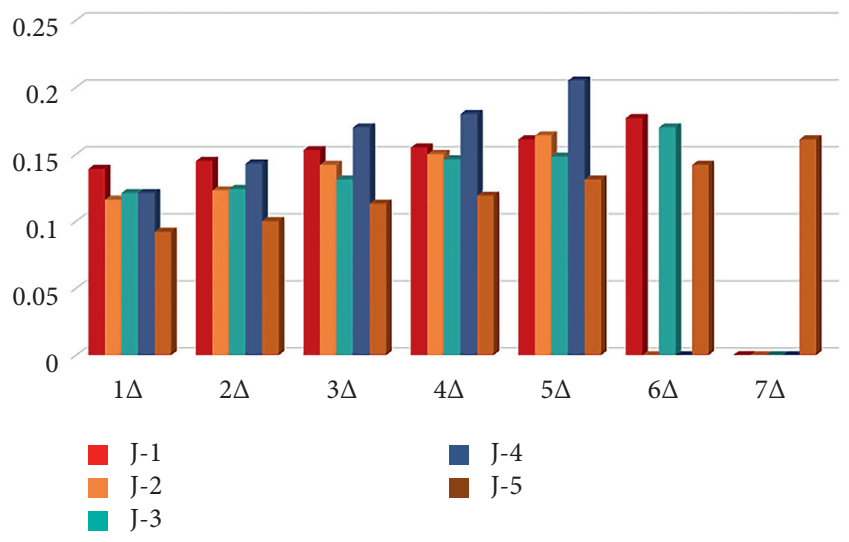

FIgURE 12: Equivalent viscous-damping coefficient.

equivalent viscous-damping coefficients of J-2 under different displacements are $0.116,0.123,0.142,0.150$, and 0.164 , showing an increasing trend. Comparing specimens $\mathrm{J}-1, \mathrm{~J}-2$, and J-3, when displacement reached $3 \Delta$, equivalent viscousdamping coefficient of J-1 (0.153) is larger than that of J-2 (0.142) and J-3 (0.131) under the same displacement, indicating that the energy absorption capacity reduces under the same loading order with the increase in the axial compression ratio. Comparing J-4 and J-5, it can be seen that the equivalent viscous-damping coefficient of J-4 (0.121) is larger than that of J-5 (0.092) under the same displacement, indicating that the energy absorption capacity of the member with cross diagonal ventral steel angle in the joint core is decreased under the same displacement.

3.5. Bearing Capacity Degradation. The bearing capacity of the structure was degraded under low-cyclic reversed loading. In particular, during the displacement control stage, the measured column end force decreases with the repetition of displacement loading cycles [26, 27]. The strength degradation of the structure can be expressed by the degree of degradation $\left(\lambda_{i}\right)$, which can be calculated according to the following formula:

$$
\lambda_{i}=\frac{P_{i}^{j}}{P_{i}^{1}},
$$

where $P_{i}^{j}$ is the peak load of the $j^{\text {th }}$ cycle under the displacement of the $i^{\text {th }}$ load and $P_{i}^{1}$ is the peak load of the first cycle under the control of the displacement of the $i^{\text {th }}$ load. The strength degradation curve of the specimen is shown in Figure 13. It can be seen from the figure that, under the control of the same displacement progression, the peak load of the component gradually decreases with an increase in the number of cycles. Further, the second cycle strength degradation (i.e., the corresponding value of the rectangle in the figure) is more obvious than the third cycle strength degradation (i.e., the corresponding value of the circle in the figure). With the increase in displacement, strength degradation becomes increasingly obvious. This is due to the accumulation of concrete damage and gradually peeling off the work. When the final failure occurs, the strength degradation coefficients of the five specimens are all approximately 0.8 .

3.6. Stiffness Degeneration. The secant stiffness of the structure is taken as the ratio of the maximum horizontal load in each cycle to the corresponding displacement. Figure 14 shows the stiffness degradation curves of the five joints in this test. As shown in the figure, the stiffness of the component joints decreases with an increased load displacement. With the gradual yield of steel bone, concrete damage accumulates, cracks develop further, and stiffness degradation slows and finally tends to become stable. The stiffness of the member with more steel in the core area is larger and the stiffness degradation is slowed. With the 

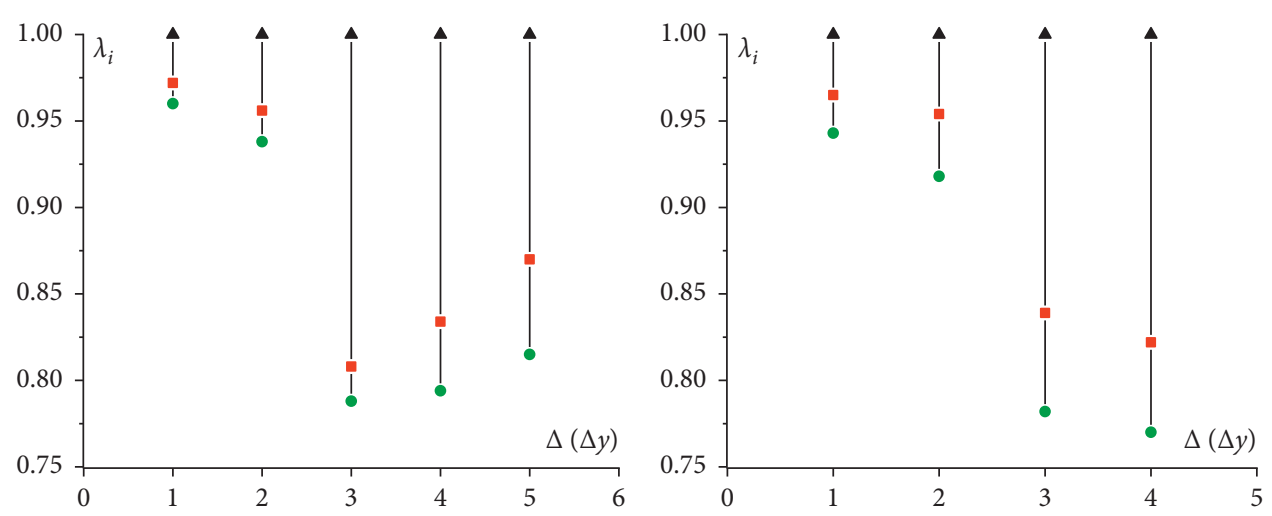

(a)

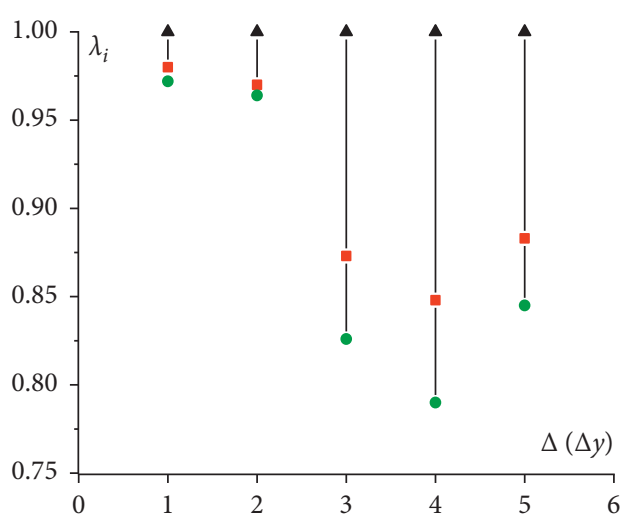

(c)

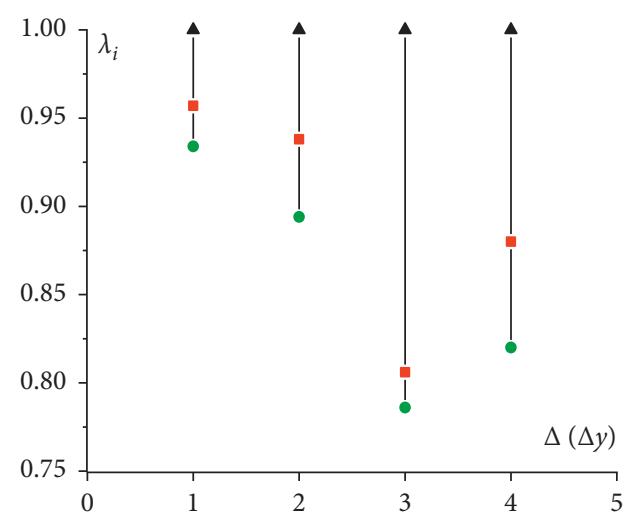

(d)

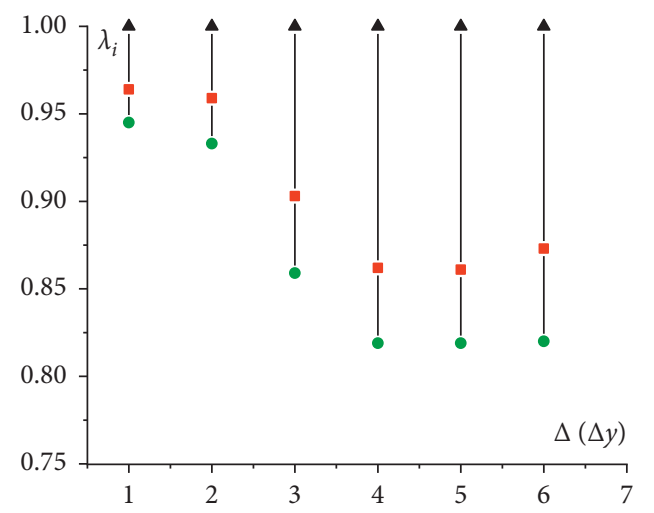

(e)

FIgURE 13: Bearing capacity degradation. (a) J-1, (b) J-2, (c) J-3, (d) J-4, and (e) J-5.

increase in the axial compression ratio, the initial stiffness of the component can be improved but the stiffness degenerates faster during the late loading period.

3.7. Component Strain Analysis. In the low-cycle reciprocating test of the joint, the resistance strain gauge collected and recorded the strain changes to the relevant measuring points. Meanwhile, during the test loading process, the load displacement of the column end at the key time node should be marked on the strain gauge. To facilitate the analysis, the corresponding displacement and strain values recorded in the first cycle of loading at each stage in the positive direction were taken, and the displacement-strain curve was drawn. 


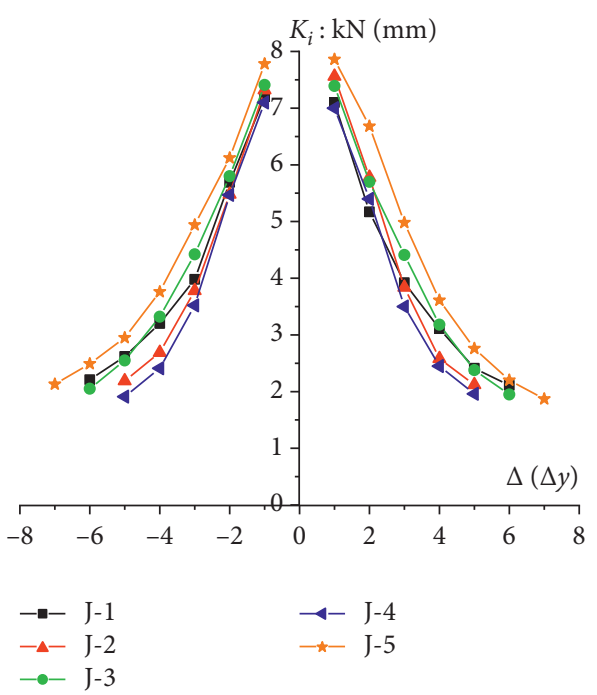

Figure 14: Stiffness degeneration.

After a simple comparison, the change law of the load strain of the five specimens was similar. Thus, one of the specimens was selected to illustrate the change law of strain at the relevant measurement points.

3.8. Strain of Angle Steel of Beam End Chord. A typical specimen J-2 is taken as an example to analyze the chord strain at the end of the beam. The strain of the angle steel of the beam end chord is shown in Figure 15. It can be seen from the diagram that before the specimen displacement reaches the yield displacement, the strain increases linearly with the displacement. After the displacement reaches $1 \Delta$ $(15 \mathrm{~mm})$, the strain of the measuring point appears at the inflection point. When the displacement reaches $3 \Delta$, the strain peaks at $1650 \mu \varepsilon$. At this point, the chord angle yields. Then, as the displacement continues to increase, the strain at the measured point decreases. This is because the rapid development of cracks aggravates the concrete damage.

3.9. Strain of Angle Steel of Column End Chord. A typical specimen $\mathrm{J}-1$ is taken as an example to analyze the strain of the angle steel of the column end chord. It can be seen from Figure 16 that when the displacement reaches $3 \Delta$, the chord angle steel strain peaks at $1278 \mu \varepsilon$. During the entire test process, the angle steel of the column end chord does not reach the yield strength, which is consistent with the design idea of the strong column and weak beam proposed in this paper.

3.10. Strain of Longitudinal Reinforcement Chord of BeamColumn in the Core Area. A typical specimen J-5 is taken as an example to analyze the strain of the longitudinal reinforcement chord of the beam-column in the core area. It can be seen from Figure 17 that, during the early loading stage, the chord of the core beam was elastic. When the displacement load was $1 \Delta$, the chord angle did not succumb. When the displacement load was $2 \Delta$, the chord strain exceeded the yield strain. When the displacement load was $6 \Delta$, the component damage and strain reached $3850 \mu \varepsilon$.

3.11. Strain of Cross Diagonal Bar of the Core Area. A typical specimen J-3 is taken as an example to analyze the strain of the cross diagonal bar of the core area. It can be seen from Figure 18 that the strain value of the cross-angle steel is larger at the beginning of loading. When the displacement load was $1 \Delta$, the oblique abdominal rod strain increased rapidly to $1600 \mu \varepsilon$. The oblique rods yielded and cross oblique cracks appeared in the core area. When the displacement load was $2 \Delta$, the angle strain reached $4850 \mu \varepsilon$. When the displacement load was $3 \Delta$, the angle strain was considerably greater than the yield strain, and the oblique abdominal rod angle entered the intensive phase. Subsequently, the strain gauge of the oblique bar was not recorded owing to excessive deformation and damage. The strain gauge reading of the oblique strut verifies that the core area of the component joint is subjected to the maximum stress, which is consistent with the "weak joint" proposed in this paper.

3.12. Shear Deformation of the Joint Core Region. As shown in Figure 19, the core shape distorts into a diamond under the action of the force; under low-cycle loading, the shape of the diamond will vary based on the two core diagonal position settings. A displacement meter is then used to measure the deformation of the two directions and calculate the shear angle, gamma, according to equation (4). Table 8 lists the five specimen nodes under the yield load, peak load, and failure load of the shear angle.

$$
\gamma=\alpha_{1}+\alpha_{2}=\frac{\sqrt{a^{2}+b^{2}}}{2 a b\left(a_{1}+a_{2}+b_{1}+b_{2}\right)},
$$

where $a_{1}$ and $a_{2}$ are measured by LVTD ${ }_{1}$ and $b_{1}$ and $b_{2}$ are measured by $\mathrm{LVTD}_{2}$.

It can be seen from Table 8 that increasing the axial pressure at the top of the column and increasing the amount of steel in the core zone can reduce the shear deformation in the core zone. This is because the increase in axial pressure is equivalent to a certain constraint on the core zone of the joint and the crack does not develop easily. Similarly, the existence of cross-angle steel can absorb part of the horizontal shear force in the core area, and the cracking and deformation of concrete will be delayed.

\subsection{Calculation of Shear Capacity of STRC Beam-Column Joints}

3.13.1. Calculation of Horizontal Shear Force in the Joint Core Area. The force diagram of the joint is shown in Figure 20. In Figure 20, $T_{t}, C_{t}$ are the tensile pressure from the chord at the beam end; $T_{b}$ and $C_{b}$ are the tensile pressure from the lower chord of the beam end; $V_{c}$ is the horizontal shear force of the column end and its value is the load value applied by the column end; $V_{b}$ is the beam end reaction; MB1 and MB2 are the bending moment of the beam ends; $M_{b 1}$ and $M_{b 2}$ are 


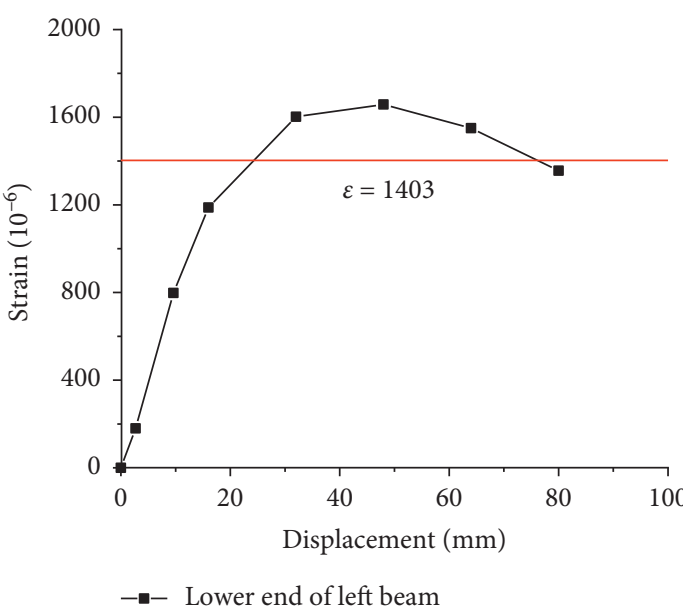

(a)

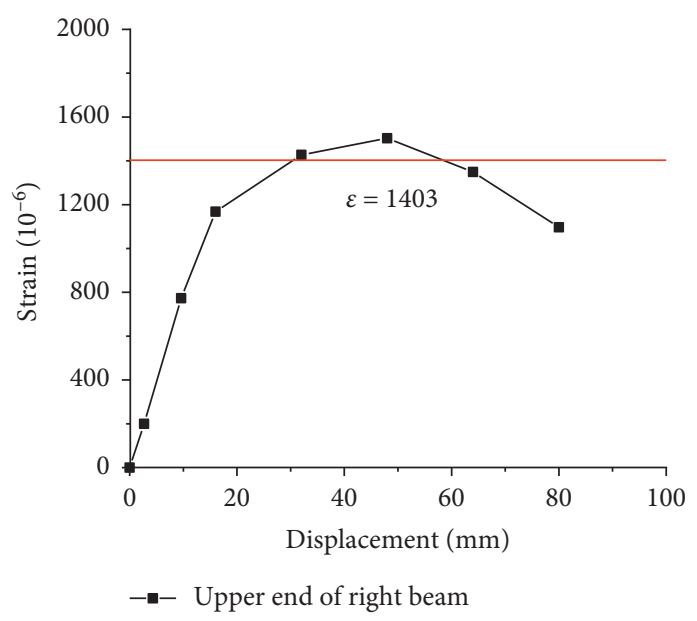

(b)

Figure 15: Strain of angle steel of beam end chord ( $\varepsilon$ means strain): (a) angle steel of lower end of left beam and (b) angle steel of upper end of right beam.

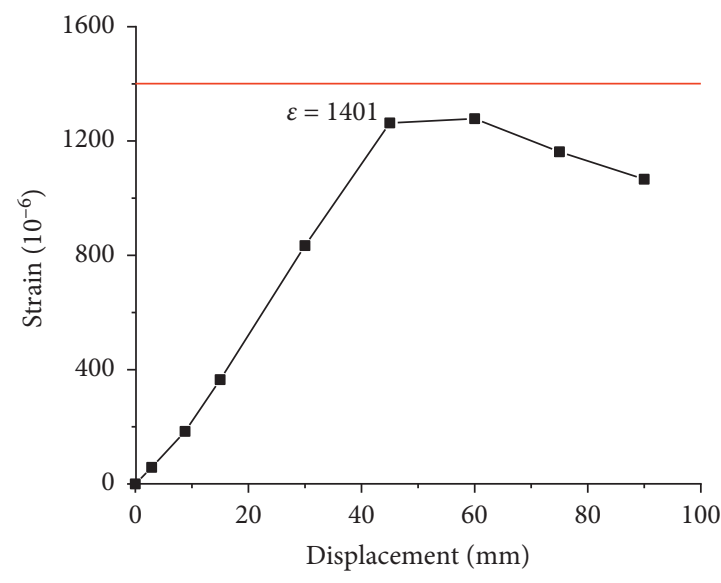

Left chord of lower column end

(a)

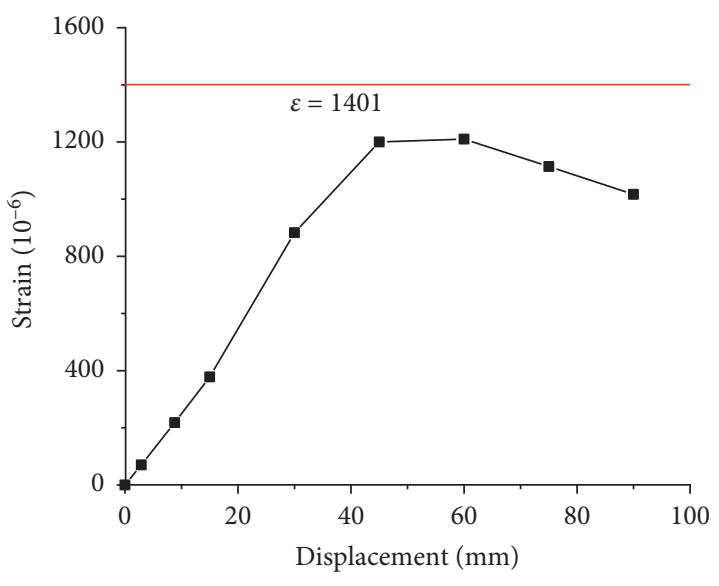

Right chord of upper column end

(b)

FIGURE 16: Strain of angle steel of column end chord: (a) angle steel of left chord of lower column end and (b) angle steel of right chord of upper column end.

the bending moments of the upper and lower column ends, respectively; $h_{1}$ and $h_{2}$ are the distance between the position of the reverse bending point of the upper and lower columns, respectively, and the core area of the joint; and $h_{b}$ is the height of beam section.

The horizontal shear force formula of the core zone is as follows:

$$
V_{j}=\frac{M_{b 1}+M_{b 2}}{h_{b w}}\left(1-\frac{h_{b w}}{h-h_{b}}\right) .
$$

According to equation (5), the horizontal shear forces in the core area of the five component nodes in the test are obtained, as listed in Table 9 .
3.13.2. Calculation of Shear Capacity of the Core Joint Area. The shear capacity of the beam-column joint of STRC is derived from two parts: the cross-inclined bar and concrete. Under the action of a horizontal earthquake, the external force of the load will transfer the force between the bearing elements and, eventually, lead to failure of the bearing elements after yielding.

The shear capacity of the diagonal bar in the STRC joints can be used to calculate the bending reinforcement in ordinary reinforced concrete. The shear force borne by the diagonal bar is equal to its component force value in the horizontal direction, as shown in Figure 21, which is calculated as follows: 


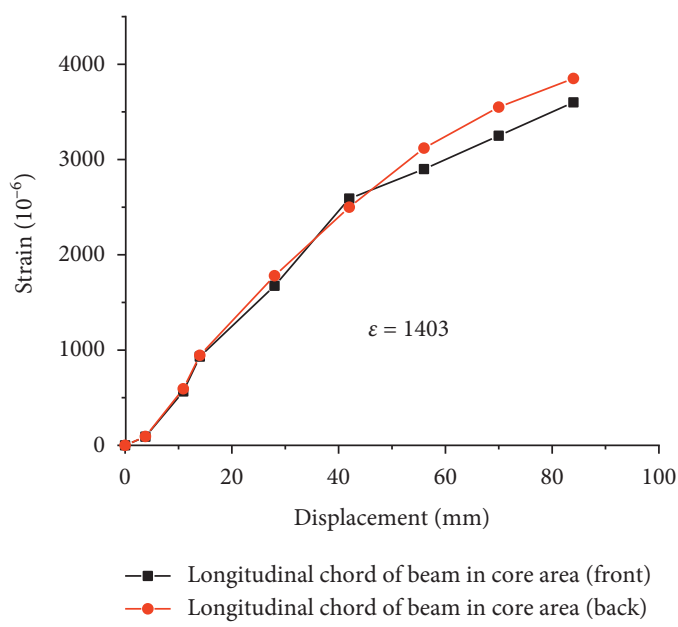

(a)

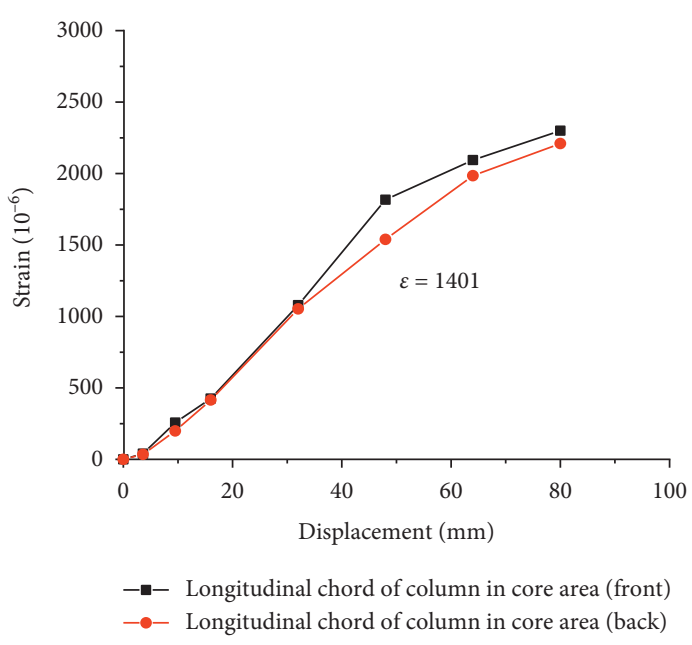

(b)

FIGURE 17: Strain of longitudinal reinforcement chord of beam-column in the core area: (a) longitudinal chord of beam in core area and (b) longitudinal chord of column in core area.

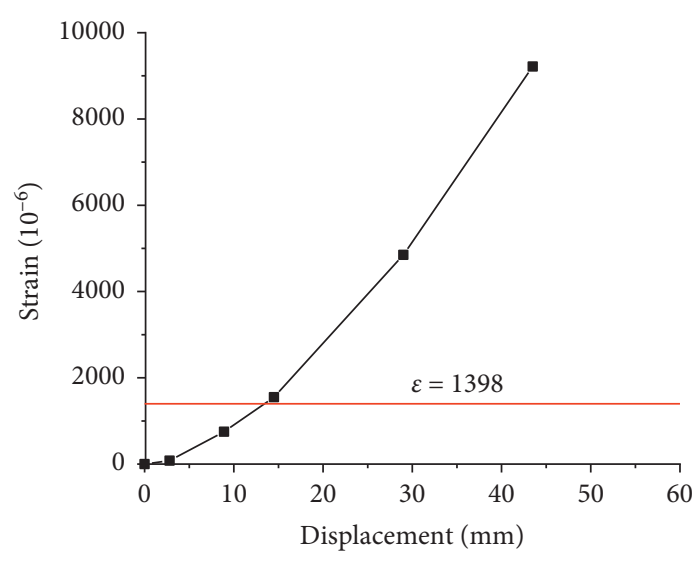

Strain of cross diagonal bar of core area

FIGURE 18: Strain of cross diagonal bar of the core area.
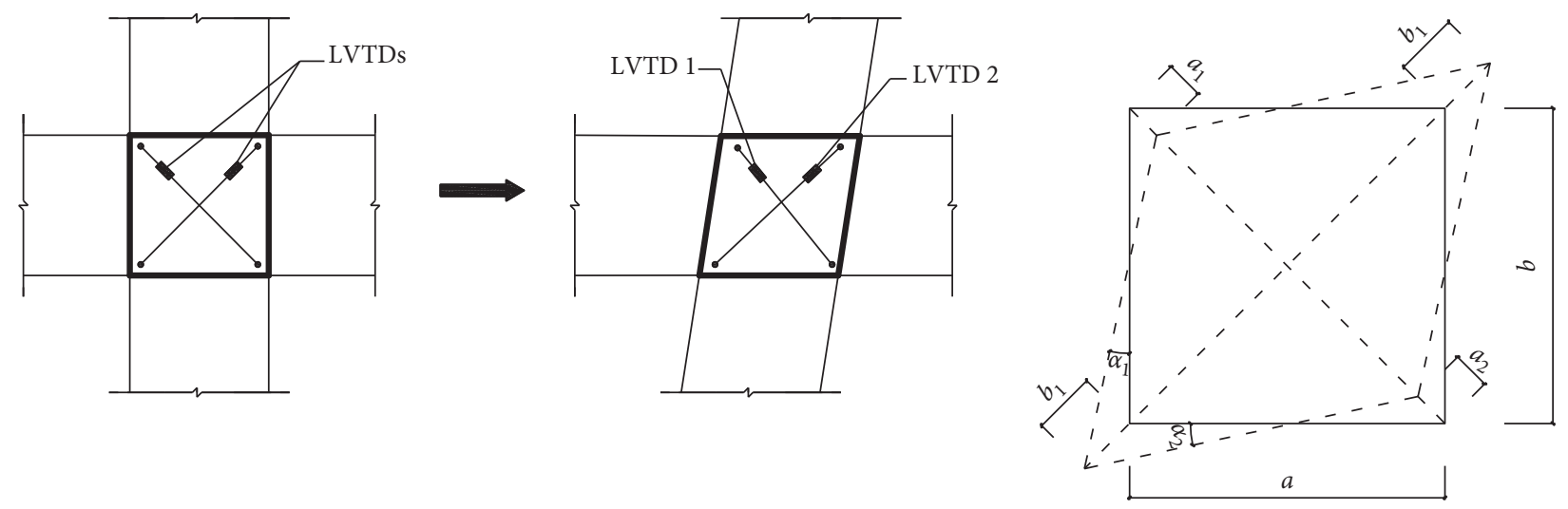

(a)

(b)

Figure 19: Core shear deformation: (a) schematic diagram of frame joint before and after deformation and (b) diagram of shear angle. 
TABLE 8: Shear angle of the core region.

\begin{tabular}{|c|c|c|c|}
\hline Specimen number & Shear angle of yield load & Shear angle of peak load & Shear angle of failure load \\
\hline $\mathrm{J}-1$ & $5.3 \times 10^{-3}$ & $1.5 \times 10^{-2}$ & $5.3 \times 10^{-2}$ \\
\hline$J-2$ & $3.6 \times 10^{-3}$ & $1.2 \times 10^{-2}$ & $4.1 \times 10^{-2}$ \\
\hline$J-3$ & $2.8 \times 10^{-3}$ & $9.2 \times 10^{-3}$ & $3.1 \times 10^{-2}$ \\
\hline$J-4$ & $4.1 \times 10^{-3}$ & $1.4 \times 10^{-2}$ & $4.3 \times 10^{-2}$ \\
\hline $\mathrm{J}-5$ & $3.4 \times 10^{-3}$ & $1.0 \times 10^{-2}$ & $3.7 \times 10^{-2}$ \\
\hline
\end{tabular}

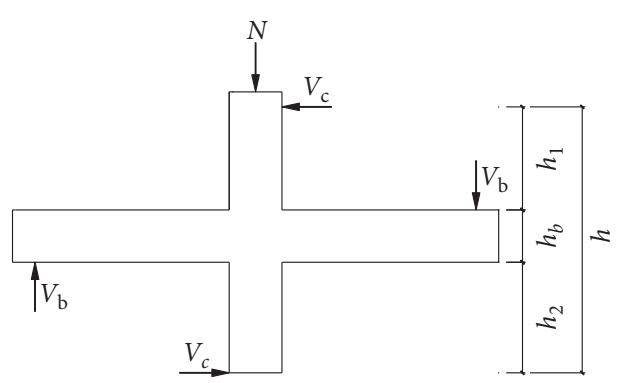

(a)

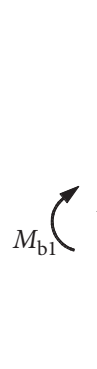

(1)

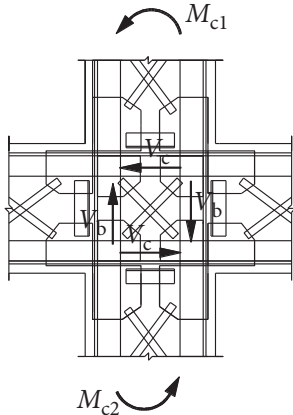

(b)

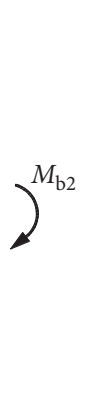

$M_{\mathrm{b} 2}^{\stackrel{C_{\mathrm{t}}}{\longrightarrow}} \stackrel{T_{\mathrm{b}}}{\longrightarrow}$

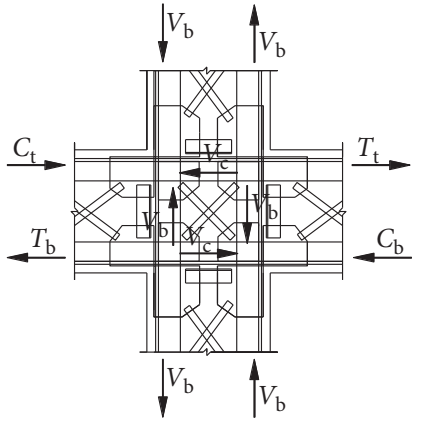

(c)

Figure 20: Nodal force relation.

TABLE 9: Horizontal shear forces in the core area.

\begin{tabular}{lc}
\hline Specimen number & Horizontal shear forces in the core area: $\mathrm{kN}$ \\
\hline J-1 & 901.43 \\
J-2 & 935.69 \\
J-3 & 954.19 \\
J-4 & 891.33 \\
J-5 & 1007.47 \\
\hline
\end{tabular}

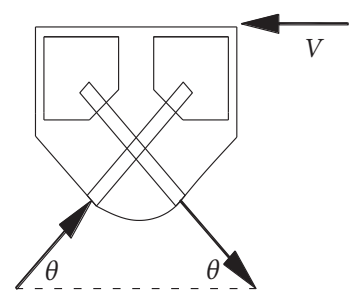

FIGURE 21: Shearing force undertaken by the oblique ventral bar.

$$
V_{s w}=f_{s w} A_{s w} \cos \theta
$$

where $V_{s w}$ is the contribution value of the cross-angled bars to the shear bearing capacity of the core area, $f_{s w}$ is the tensile yield strength of the oblique girder, and $A_{s w}$ is the sum of the cross-sectional area of the oblique girder in the core area. $\theta$ is the angle between the oblique bar and the horizontal.

According to the stress mechanism of concrete baroque bars in the core area, the contribution of concrete to the shear capacity of STRC joints can be expressed as follows, where $H$ is the equivalent width of the concrete baroclinic bar in the core area of the joint and $b_{j}$ is the effective shear height in the core area of the joint; and its value is $b_{j}=\left(h_{c}+h_{b}\right) / 2 . f_{c}$ is the compressive strength of the concrete in the core area of the joint. $\theta$ is the angle between the baroclinic bar and the horizontal plane.

$$
V_{c}=H b_{j} f_{c} \cos \theta
$$

According to different joint types, $H$ can be expressed by a certain ratio of the diagonal line of the core region, which can be expressed as follows, where $h_{c}$ is the height of the column section, and its value is equal to the height of the joint $h_{j} ; h_{b}$ is the height of the beam section, which can be expressed as a certain ratio of the column section height; that is, $h_{b}=\beta h_{c}=\beta h_{j}$.

$$
H=\alpha \sqrt{h_{j}^{2}+\beta^{2} h_{j}^{2}}=\alpha h_{j} \sqrt{1+\beta^{2}} .
$$

Let $\xi=\cos \theta \alpha\left(1+\beta^{2}\right)^{0.5}$. Then, the shear bearing capacity of concrete in the joint core area can be expressed as

$$
V_{c}=H b_{j} f_{c} \cos \theta=\xi b_{j} f_{c} h_{j}
$$

where $\xi$ is the coefficient to be determined and it denotes the shear influence coefficient of concrete, which synthesizes the constraint effect of the core area of the column top axial compression joint on the concrete joint; this can be obtained by subtracting the horizontal limit shear $V_{j}$ of the core area of the joint from the shear contribution value $V_{s w}$ of the cross skew bar calculated above. The specific undetermined coefficient $\xi$ can be obtained from the following:

$$
\xi=\frac{V_{j}-V_{s w}}{f_{c} b_{j} h_{j}} .
$$

Through preliminary data analysis, it is found that the influence of the axial compression ratio $n$ should be 


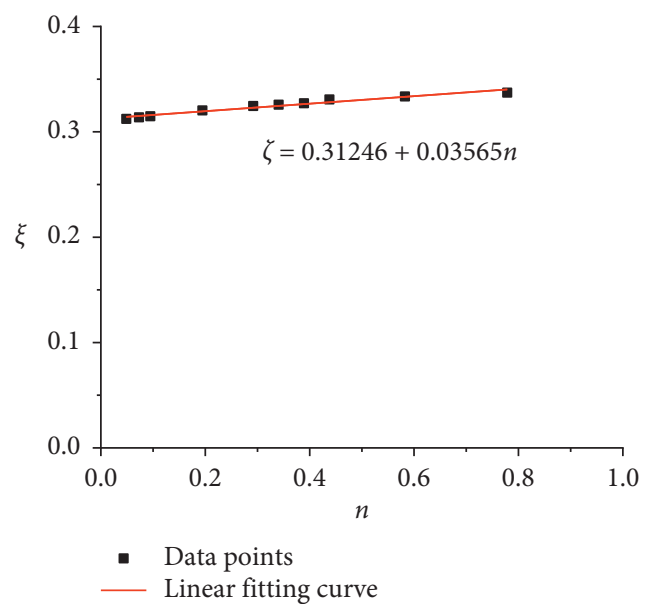

FIGURE 22: Concrete bearing capacity contribution fitting diagram.

TABLE 10: Comparison of test and calculation values of shear capacity.

\begin{tabular}{lccc}
\hline Specimen number & Calculated value: $\mathrm{kN}$ & Experimental value: $\mathrm{kN}$ & Ratio of test and calculated values \\
\hline $\mathrm{J}-1$ & 889.28 & 901.43 & 1.01 \\
$\mathrm{~J}-2$ & 893.20 & 935.69 & 1.05 \\
$\mathrm{~J}-3$ & 897.12 & 954.19 & 1.06 \\
J-4 & 803.84 & 891.33 & 1.11 \\
J-5 & 1048.20 & 1007.47 & 0.96 \\
\hline
\end{tabular}

considered to determine the coefficient $\xi$. Therefore, by using Origin software, the relationship between the undetermined coefficient $\xi$ and axial compression ratio $\mathrm{N}$ under different parameters is obtained through linear fitting. The fitting result is shown in Figure 22 and the specific expression is as follows:where $n=\left(N / f_{c} A_{c}+t f_{s}^{\prime} n A_{s s}\right)$ (here, $N$ is the designed axial force at the top of the column, $A_{c}$ is the net concrete area of the column section, $A_{\mathrm{ss}}$ is the sum of the angle steel area of the column section chord, and $f_{s}^{\prime}$ is the compressive strength of the angle steel).

$$
\xi=0.31246+0.03565 n
$$

The shear bearing capacity formula obtained in this study is derived under a monotonic load. Considering that the peak load under the low-cycle reciprocating action of the test is slightly less than the monotonic simulated load, $\xi$ is slightly weakened when calculating the bearing capacity of STRC beam-column joints, and the following formula is suggested for use:

$$
\xi=0.25+0.03 n
$$

In summary, the shear capacity of trussed SRC beamcolumn joints comprises the superposition of the shear capacity $\left(V_{s w}\right)$ of the inclined rod in the core area and the shear capacity $\left(V_{c}\right)$ of the concrete. The specific shear capacity formula is as follows:

$$
V_{c}=(0.25+0.03 n) f_{c} b_{j} h_{j}+f_{s w} A_{s w} \cos \theta .
$$

3.13.3. Verification of Shear Bearing Capacity Formula for the Core Joint Area. According to Table 10, using the oblique compression bar model to calculate the shear bearing capacity of the STRC beam-column joints is in good agreement with the test results; hence, the formula can be applied to similar types of shear bearing capacity calculations on openweb SRC structures.

\section{Conclusions}

In this experiment, low-cycle reciprocating load tests were conducted on five specimen joints, and the loading and failure processes were observed. Through the load-displacement hysteresis curves recorded by the actuators, the influences of different parameters on the ductility, energy dissipation capacity, stiffness degradation, and strength degradation of the joints were analyzed. In addition, the strain and displacement of the key parts were collected by the strain gauge and displacement gauge to verify the concrete force, deformation, and failure process of the specimen. The specific conclusions are as follows:

(a) The load-displacement hysteresis curve of this type of specimen shows a pinching phenomenon as the angle steel used in this study had a smoother surface than an ordinary steel bar and a larger contact area with concrete, resulting in slip between the concrete and steel bone. The hysteresis curve of specimen J-4 is relatively full, and the bond relationship between the steel bone and concrete in the core area is good. 
(b) The bearing capacity and ductility of the specimen can be effectively improved by setting the cross diagonal bar angle steel in the core area of the joint steel, while the stiffness is larger and the degradation is slower.

(c) The axial compression ratio is beneficial for increasing the bearing capacity of the specimen, but its energy dissipation capacity and ductility are decreased.

(d) The calculation results of the proposed formulas for the shear bearing capacity of the joints in STRC beam-column frames are lower than the simulated values and are in good agreement with the experimental results. Therefore, it is safe and reasonable to design the shear bearing capacity of such joints according to the baroclinic bar model.

\section{Data Availability}

The test data are included in the article and can be made freely available.

\section{Conflicts of Interest}

The authors declare that they have no conflicts of interest.

\section{Acknowledgments}

The work described in this paper was supported by grants from the National Natural Science Foundation of China (Grant no. 51578478), the Natural Science Foundation of Jiangsu Province (Grant no. BK20201436), the China Postdoctoral Science Foundation (Project no. 2018M642335), the Science and Technology Project of Jiangsu Construction System (Grant no. 2018ZD047), the Blue Project Youth Academic Leader of Colleges and Universities in Jiangsu Province (2020), and the Six Talent Peaks Project of Jiangsu Province (JZ-038, 2016).

\section{References}

[1] T. V. Galambos, "Recent research and design developments in steel and composite steel-concrete structures in USA," Journal of Constructional Steel Research, vol. 55, no. 1-3, pp. 289-303, 2000.

[2] J. A. Abdullah, S. M. Zhang, and J. P. Liu, "Shear strength and behavior of tubed reinforced and steel reinforced concrete (TRC and TSRC) short columns," Thin-Walled Structures, vol. 48, pp. 191-199, 2011.

[3] K.-H. Yang, A. F. Ashour, and E.-T. Lee, "Axial behaviour of reinforced concrete short columns strengthened with wire rope and T-shaped steel plate units," Magazine of Concrete Research, vol. 61, no. 2, pp. 143-154, 2009.

[4] Y. Y. He, Study on Seismic Behavior of Steel-Reinforced Concrete Beam-Column Joints, Hefei University of Technology, Hefei, China, 2012.

[5] R. Kanno, Strength, Deformation, and Seismic Resistance of Joints between Steel Beams and Reinforced Concrete Columns, Cornell University, Ithaca, NY, USA, 1993.

[6] R. Kanno and G. G. Deierlein, "Seismic behaviour of composite (RCS) beam-column joint subassemblies," in
Proceedings of the 1996 Engineering Foundation Conference on Composite Construction in Steel and Concrete III, pp. 236-249, Irsee, Germany, June 1996.

[7] K. Ryoichi, "Cycle behavior and seismic resistance of joints between steel beams and reinforced concrete columns," in Proceedings of the Structures Congress XII. ASCE, Atlanta, GA, USA, April 1994.

[8] C.-C. Chou and C.-M. Uang, "Cyclic performance of a type of steel beam to steel-encased reinforced concrete column moment connection," Journal of Constructional Steel Research, vol. 58, no. 5-8, pp. 637-663, 2002.

[9] R. Kadarningsih, I. Satyarno, Muslikh, and A. Triwiyono, "Analysis and design of reinforced concrete beam-column joint using king cross steel profile," Procedia Engineering, vol. 171, pp. 948-956, 2017.

[10] S. R. Mirghaderi, N. Bakhshayesh Eghbali, and M. M. Ahmadi, "Moment-connection between continuous steel beams and reinforced concrete column under cyclic loading," Journal of Constructional Steel Research, vol. 118, pp. 105-119, 2016.

[11] C.-C. Chen, B. Suswanto, and Y.-J. Lin, "Behavior and strength of steel reinforced concrete beam-column joints with single-side force inputs," Journal Of Constructional Steel Research, vol. 65, no. 8-9, pp. 1569-1581, 2009.

[12] J. R. Tang and X. H. Chen, "Mechanical properties and shear strength of stiffened concrete beam-column joints," Journal of Building Structures, vol. 4, pp. 28-36, 1990.

[13] R. Ketiyot and C. Hansapinyo, "Seismic performance of interior precast concrete beam-column connections with T-section steel inserts under cyclic loading," Earthquake Engineering and Engineering Vibration, vol. 17, no. 2, pp. 355-369, 2018.

[14] B. C. Chen, Y. M. Mou, Y. Y. Chen et al., "Research progress and engineering application of steel-concrete composite bridge in China," Journal of Building Structures, vol. 34, pp. 1-10, 2013.

[15] C.-C. Chen and K.-T. Lin, "Behavior and strength of steel reinforced concrete beam-column joints with two-side force inputs," Journal of Constructional Steel Research, vol. 65, no. 3, pp. 641-649, 2009.

[16] J. Zeng, Study on Seismic Behavior of Joints in Trussed SRC Beam-SRC Column Frame, Guangxi University, Nanning, China, 2015.

[17] K. Chen, Study on Seismic Performance of Trussed SRC BeamSRC Column Frame Edge Joints, Guangxi University, Nanning, China, 2015.

[18] Z. H. Deng, Q. Hu, J. Zeng et al., "Structural performance of steel-truss-reinforced composite joints under cyclic loading," Structures and Buildings, vol. 171, pp. 1-19, 2017.

[19] C. G. Karayannis and E. Golias, "Strength of deficient RC Joints with diagonally placed external C-FRP sheets," Earthquakes and Structures, vol. 20, no. 1, pp. 123-132, 2021.

[20] Q. Chen, Test on Force-Displacement Mixed Control Method of Loading System with Three Degrees of Freedom, Harbin Institute of Technology, Harbin, China, 2017.

[21] M. J. Favvata, "Influence of pinching effect of exterior joints on the seismic behavior of RC frames," Earthquakes and Structures, vol. 6, no. 1, pp. 089-110, 2014.

[22] J. Ji, Study on Seismic Behavior and Design Method of Prestressed SRC Frame with Extended Layer, Harbin Institute of Technology, Harbin, China, 2008.

[23] P. Xiang, Z. Deng, Y. Su, H. Wang, and Y. Wan, "Experimental investigation on joints between steel-reinforced concrete T-shaped column and reinforced concrete beam 
under bidirectional low-cyclic reversed loading," Advances in Structural Engineering, vol. 20, no. 3, pp. 446-460, 2016.

[24] C. G. Karayannis and E. Golias, "Full scale tests of RC Joints with minor to moderate damage repaired using C-FRP sheets," Earthquakes and Structures, vol. 15, no. 6, pp. 617627, 2018.

[25] J. R. Tang, Seismic Behavior of Joints in the Reinforced Concrete Frame Structure, Southeast University Press, Nanjing, China, 1989.

[26] Y. F. Wu, "The effect of longitudinal reinforcement on the cyclic shear behavior of glass fiber reinforced gypsum wall panels tests," Engineering Structures, vol. 26, pp. 1633-1646, 2008.

[27] Y. F. Wu, "Ductility demand of compression yielding fiber reinforced polymer-reinforced concrete beams," ACI Structural Journal, vol. 105, pp. 104-110, 2008. 